Article

\title{
Thermomechanical Analysis of a Helical-Wedge Rolling Process for Producing Balls
}

\author{
Zbigniew Pater*D, Janusz Tomczak, Jarosław Bartnicki and Tomasz Bulzak \\ Mechanical Faculty, Lublin University of Technology, 36 Nadbystrzycka Str., 20-618 Lublin, Poland; \\ j.tomczak@pollub.pl (J.T.); j.bartnicki@pollub.pl (J.B.); t.bulzak@pollub.pl (T.B.) \\ * Correspondence: z.pater@pollub.pl; Tel.: +48-81-538-4242
}

Received: 4 October 2018; Accepted: 20 October 2018; Published: 23 October 2018

check for updates

\begin{abstract}
The paper presents a complete numerical model of a helical-wedge rolling process for producing balls. The model was designed in Finite Element Method (FEM)-based Forge NxT v.1.1 that enables the simulation of both forming and separating balls. A comparison of numerical results with experimental findings revealed a very high agreement in both qualitative and quantitative terms. The developed numerical model was used to investigate the effect of flange shape on the helical-wedge rolling process for producing balls with a diameter of $125 \mathrm{~mm}$. Three types of flange tools were investigated, and the best results were obtained for a wedge-shaped flange.
\end{abstract}

Keywords: helical-wedge rolling; tools; FEM; experiment

\section{Introduction}

Steel balls are widely used in the engineering industry (e.g., for producing rolling bearings), and in the processing sector as grinding media in ball mills for grinding metal ores, coal, gravel, used-up molding sands and many other materials.

Helical-wedge rolling is considered the most efficient method for producing balls. In this process, balls are formed by two rolls positioned askew relative to the axis of the billet (cylindrical rod). The roll faces have helically wound flanges, which periodically cut into the workpiece, confining in the roll pass a material volume that is equal to the volume of the ball being formed. A correct position of the billet between the rolls is maintained by guides that close the roll pass on the two other sides.

The idea of helical-wedge rolling was invented in the USA before World War 2. Nevertheless, the process was not implemented on an industrial scale until the 1950s in the former USRR [1]. Since then, one can observe a development of the helical-wedge rolling technique, and today the process can be performed using commercial rolling mills manufactured in Russia and China. Despite the sixty-year-long tradition of using helical-wedge rolling for producing balls, this process has not yet been fully investigated.

In recent years, due to a rapid development of computer hardware and software for analysis of metal forming processes, some attempts have been made to model helical-wedge rolling of balls. The first studies in this area were by published by Ren et al. [2,3], who used Deform 3D to determine the effect of basic variables (feed angle, rotational speed of the rolls, spacing between the guides) on the helical-wedge rolling process and manufacturing accuracy of produced balls. Nonetheless, the authors of these studies did not consider thermal phenomena, and only modelled the initial forming stage. A more advanced model of helical-wedge rolling was built by Pater et al. [4-6]. This model was primarily used for developing a new flange in the shape of a wedge. The model was also used for analysis of more complex cases of multi-tool rolling based on the use of rolls with two (or more) flanges in order to increase efficiency of the rolling process. Designed in Simufact. Forming, this model did not, however, offer the possibility to simulate the separation of balls connected into "chains" by means 
of small diameter bridges. A similar simplification was employed by Cao et al. [7], who used the same software to investigate the stresses and strains in a cold rolling process for producing balls with a diameter of $7.4 \mathrm{~mm}$. Finally, Filippova et al. [8] used Deform 3 to analyze the stresses in balls of two diameters (93 $\mathrm{mm}$ and $125 \mathrm{~mm}$ ), produced by hot rolling. However, they did not model the separation of balls.

Given the results of a state-of-the-art survey, a complete numerical model of a helical-wedge rolling process for producing balls was designed. An absolute novelty differentiating the discussed model from the ones used thus far is the possibility of prognosticating the separation of balls, occurring as a result of the material cracking, which happens once the damage criterion exceeds the critical value. Obtained results are reported in this paper.

\section{Experimental Tests of a Helical-Wedge Rolling Process for Producing Balls with a Diameter of $57 \mathrm{~mm}$}

The main objective of this paper is to analyze the process of forming balls with $125 \mathrm{~mm}$ diameter by helical rolling. This process could not, however, be verified in the experimental manner, due to lack of a rolling mill that would allow for rolling balls with such a big diameter. Therefore, the experimental tests were limited to rolling balls with $57 \mathrm{~mm}$ diameter (at a scale of 1:2.2). The results obtained from the tests were used to validate the discussed numerical model of helical rolling of balls, which was then used in an analysis of the influence of the flange shape on the process of rolling balls with $125 \mathrm{~mm}$ diameter.

Experiments of a helical-wedge wedge rolling process for producing balls with a diameter of $57 \mathrm{~mm}$ were carried out at the Lublin University of Technology using a specially designed rolling mill (Sigma, Lublin, Poland, Figure 1), the technical specifications of which are given in Table 1. This rolling mill is provided with a system for measuring radial loads and torques.

Helical rolls were designed specifically for the purpose of the experiments, and one of these rolls is shown in Figure 2. The rolls are provided with flanges to enable first the formation of a necking between adjacent balls and then the separation of these balls. The former is done due to the action of the wedge (described with a flank inclination angle of $45^{\circ}$ ) of gradually increasing height, the shape of which —in an advanced stage of the process_-changes into the shape of the ball being formed. Balls are separated via breaking a small diameter bridge connecting adjacent balls, which takes place as a result of big differences between the rotational speed of the bridge and the ball. In the final stage of the process, the formed balls undergo sizing to remove any remains of the connecting bridges.

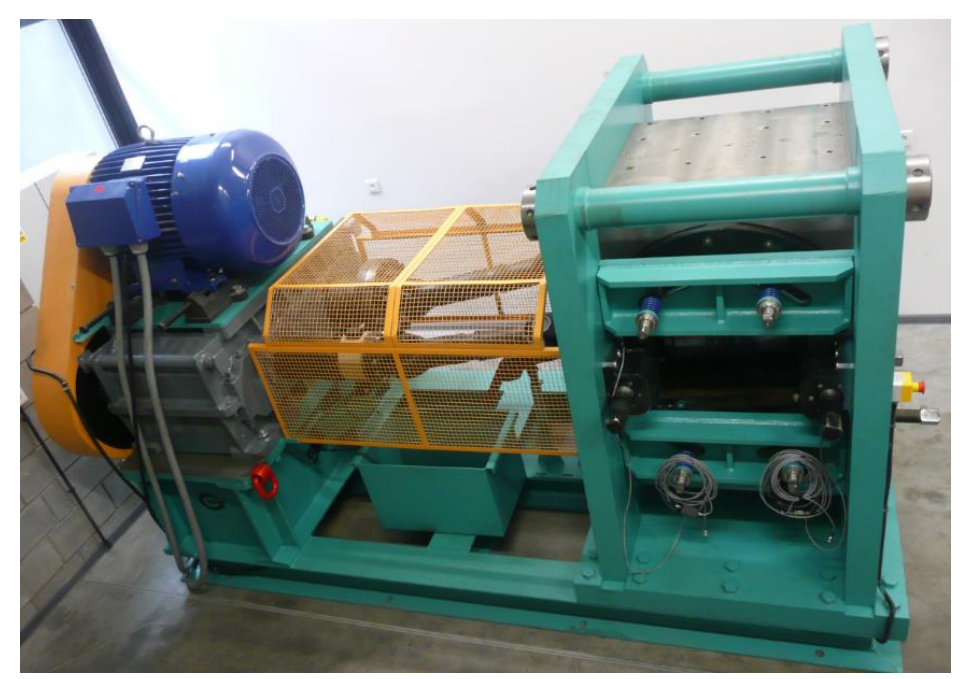

Figure 1. Skew rolling mill available at the Lublin University of Technology; technical specifications are given in Table 1. 
Table 1. Technical data of a skew rolling mill available at the Lublin University of Technology.

\begin{tabular}{cc}
\hline Parameter & Value \\
\hline Nominal Diameter of Rolls & $300 \mathrm{~mm}$ \\
Working Length of Roll Face & $400 \mathrm{~mm}$ \\
Spacing Between Roll Axes: Maximum/Minimum & $350 \mathrm{~mm} / 300 \mathrm{~mm}$ \\
Rotational Speed of Rolls & $30 / 15 \mathrm{rpm}$ \\
Engine Power & $60 / 80 \mathrm{~kW}$ \\
Dimensions: Length $\times$ Width $\times$ Height & $3200 \times 1800 \times 2100 \mathrm{~mm}^{3}$ \\
Machine Weight & $17,500 \mathrm{~kg}$ \\
\hline
\end{tabular}

Figure 3 shows a set of tools used for rolling $57 \mathrm{~mm}$ diameter balls. Apart from two identical rolls made in accordance with Figure 2, the set also includes two linear guides for maintaining the workpiece in its correct position during rolling.

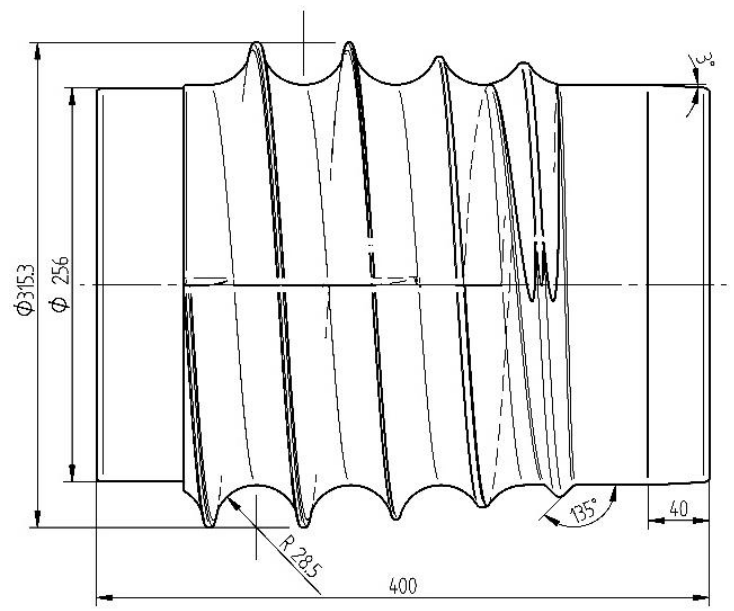

Figure 2. Schematic design of a helical roll used in experiments.

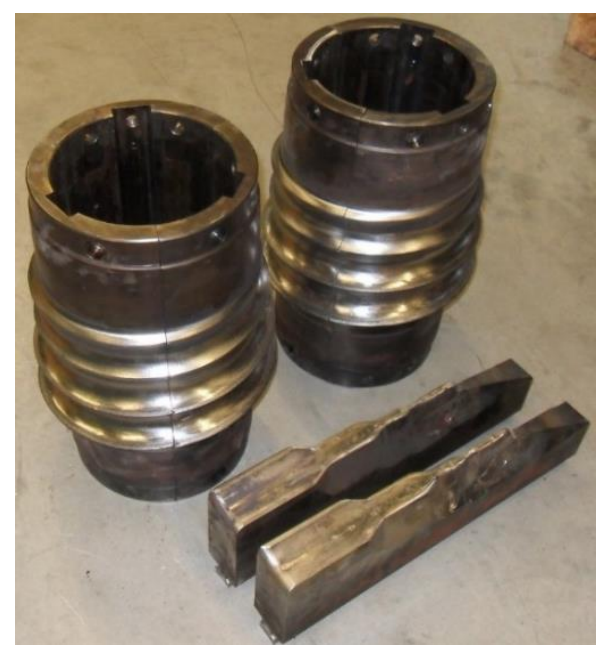

Figure 3. Tool set used in experimental helical rolling of $57 \mathrm{~mm}$ diameter balls.

Balls are shaped from rods with a diameter of $55 \mathrm{~mm}$ and a length of $600 \mathrm{~mm}$, made of C60 steel. The rods are first preheated in an electric chamber furnace to a temperature of $1050{ }^{\circ} \mathrm{C}$. After that, they are put in a tubular feed and pulled into the work space of the rolling mill by the rolls (due to their skew positioning relative to the axis of the billet). Finished balls leave the machine on the other side of the rolling stand and roll down the chute into a container (Figure 4). 

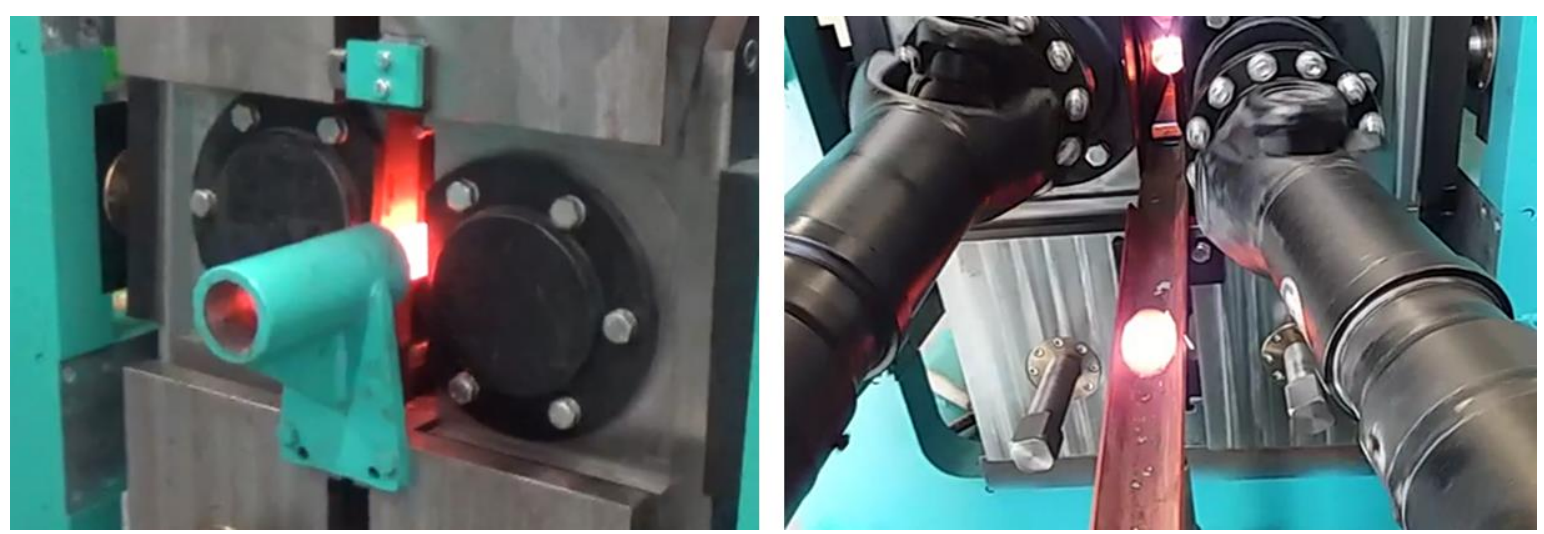

Figure 4. Helical rolling of $57 \mathrm{~mm}$ diameter balls: automatic feed of the billet (left), removal of produced balls (right).

Balls obtained in the experiments have the required shape (Figure 5). They are free from any surface defects and internal cracking. The measurements demonstrate that the balls have a diameter of $57.4 \pm 0.5 \mathrm{~mm}$, which means that they fully meet the requirements for balls used as grinding media in steel balls, where the permissible diameter tolerance is as high as $\pm 3 \mathrm{~mm}$.

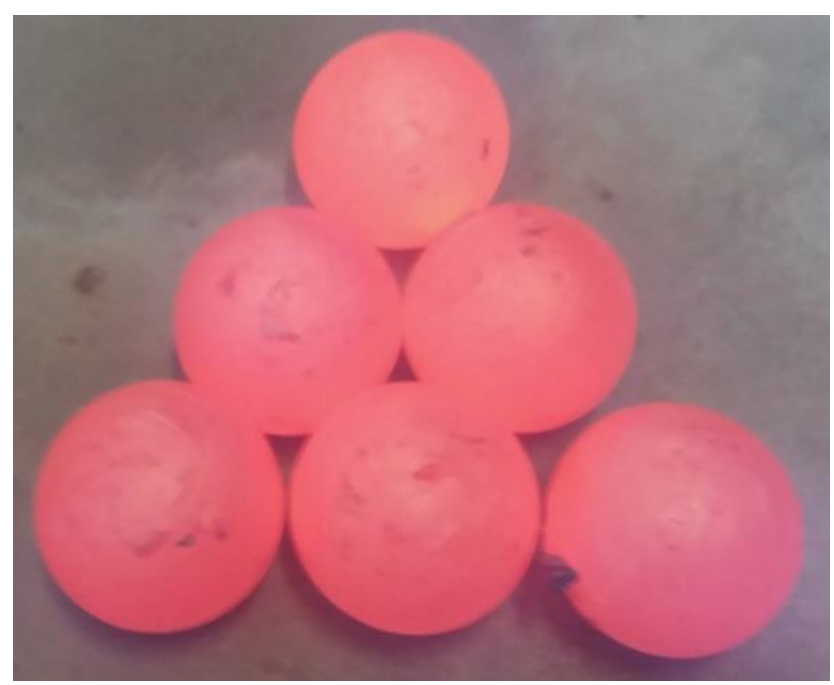

Figure 5. Balls with a diameter of $57 \mathrm{~mm}$, produced in helical rolling experiments carried out at the Lublin University of Technology.

\section{Numerical Simulation of a Helical-Wedge Rolling Process for Producing Balls with a Diameter of $57 \mathrm{~mm}$}

The investigated helical-wedge rolling process for producing $57 \mathrm{~mm}$ diameter balls was modelled numerically in FEM-based simulation software, Forge NxT v1.1 (Version 1.1, Transvalor, Sophia Antipolis, France). A geometrical model of this rolling process is shown in Figure 6. This model consists of a billet, two helical rolls (set askew at an angle of $\theta=3^{\circ}$ relative to the axis of the billet and made in accordance with Figure 2) and two linear guides. The rolls are rotated in the same direction with a rotational speed set equal to $30 \mathrm{rev} / \mathrm{min}$. 


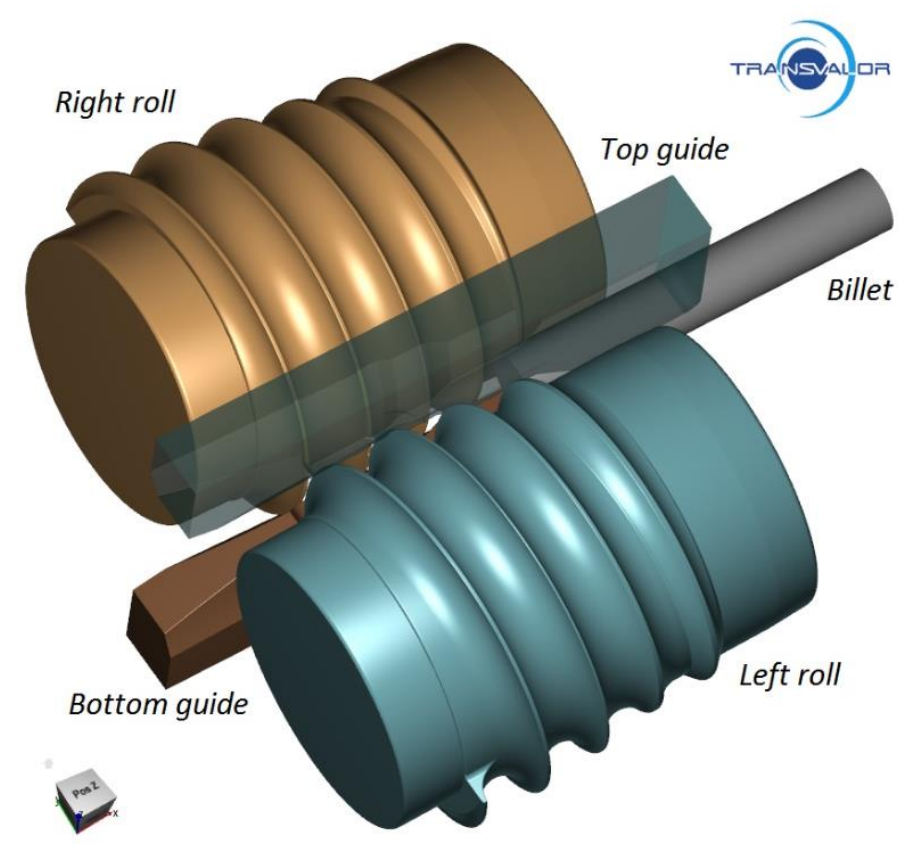

Figure 6. Geometric model of a helical rolling process for producing $57 \mathrm{~mm}$ diameter balls, designed in Forge NxT v.1.1.

The billet had a diameter of $55 \mathrm{~mm}$ and a length of $300 \mathrm{~mm}$ and was preheated to $1050{ }^{\circ} \mathrm{C}$, while the temperature of the tools was set equal to $50{ }^{\circ} \mathrm{C}$. The material model of $\mathrm{C} 60$ steel was obtained from the software's material database library. Friction on the material-tool contact surface was described with constant friction conditions and the friction factor was set equal to 0.8 . The coefficient of thermal conductivity between the workpiece and the tools was set equal to $10,000 \mathrm{~W} / \mathrm{m}^{2} \cdot \mathrm{K}$.

When modelling rolling processes for balls, the greatest difficulty is to simulate the operation of separating balls. To do so, it is necessary to adopt the limit damage function beyond which the material begins to crack. The cracking itself is modelled via deleting the elements, in which the damage function is higher than critical value obtained in the experiments. Nonetheless, critical values obtained in tensile and compressive tests [9] are too low to ensure effective modelling of material cracking in cross and skew rolling process. This is due to the fact that experimental and numerical stress states differ. Therefore, it is necessary to devise a new test that would enable determination of the critical damage function for periodically varying stresses, as is the case in cross and skew rolling. It seems that rotary compression can be such test, as preliminarily described in [10]. Nevertheless, given a lack of results obtained from the rotary compression test, arbitrarily increased limit values obtained in tensile tests are used to this end [11]. Taking account of the results [12], the limit value of the Cockroft-Latham damage function in the simulation was assumed to be equal to 3 .

Given the complexity of the problem, the numerical simulation was performed for the first $15 \mathrm{~s}$ of rolling $57 \mathrm{~mm}$ diameter balls. In this time interval, the rolls are rotated 7.5 times, which is sufficient to produce at least two balls.

The developed FEM model of a helical-wedge rolling process for balls was verified by comparing changes in the workpiece shape. To this end, the rolling mill was stopped in the course of the forming process and the rolls were moved apart to take out the workpiece. Next, based on the diameters of the bridges connecting adjacent balls, the angle of rotation of the rolls at which the process has been halted was determined. The value of rotation angle suffices to identify this moment of the rolling process in the numerical simulation and to compare the workpiece shape (experimental and numerical), as shown in Figure 7. Results given in the figure show a perfect agreement. This observation particularly refers to the shape of produced balls that have small remains of the connecting bridges. These remains are 
ultimately removed during the sizing stage. It should be emphasized that the balls were separated correctly, which means that the applied limit damage function value was correct.

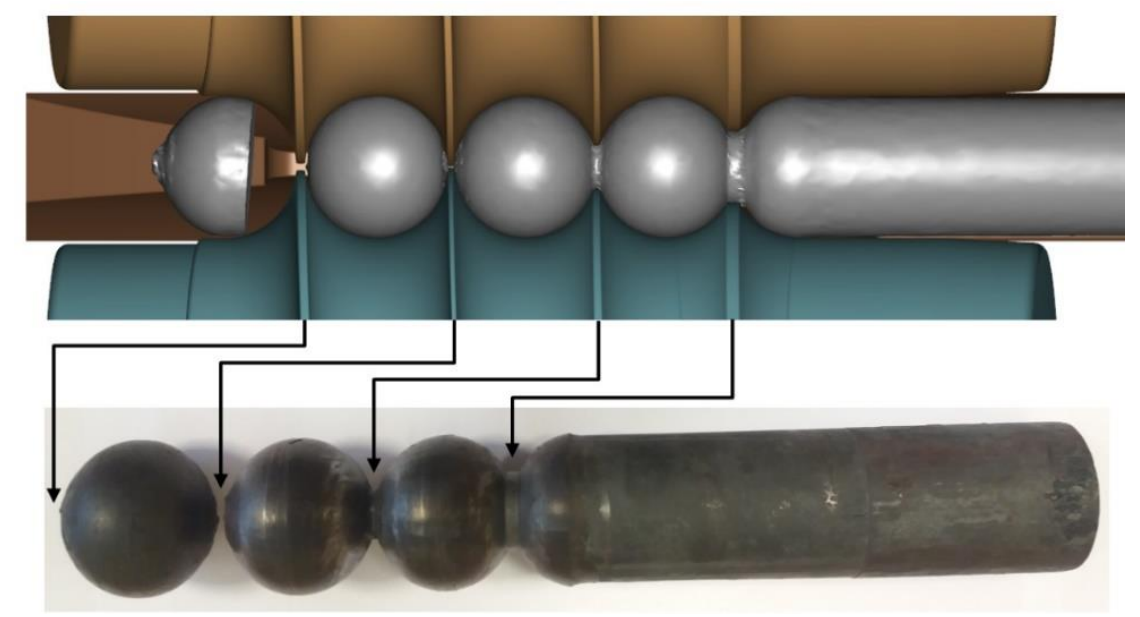

Figure 7. Shape changes in $57 \mathrm{~mm}$ diameter balls: FEM (top), and experimental (bottom).

The experiments also involved measuring the radial load (acting on the rolls) and the torque. Obtained experimental data were compared with the numerical radial load (Figure 8) and torque (Figure 9). The force parameters show a high qualitative agreement and are characterized by period variations, which results from the periodic cutting of the tool into the workpiece.

For the purpose of quantitative comparison, an area $\mathrm{F}$ under the plots of loads and torques was calculated for a time interval ranging from $0 \mathrm{~s}$ to $15 \mathrm{~s}$. After that, the error $\Delta$ was determined with the formula:

$$
\Delta=100 \% \frac{\left|F_{\mathrm{FEM}}-F_{\mathrm{Exp}}\right|}{F_{\mathrm{Exp}}}
$$

where $F_{\mathrm{FEM}}$ is the area under the numerical plots of radial load and torque, $F_{\mathrm{Exp}}$ is the area under the experimental plots.

Thereby calculated errors were as follows $-2.6 \%$ for the torque and $2.0 \%$ for the radial load.

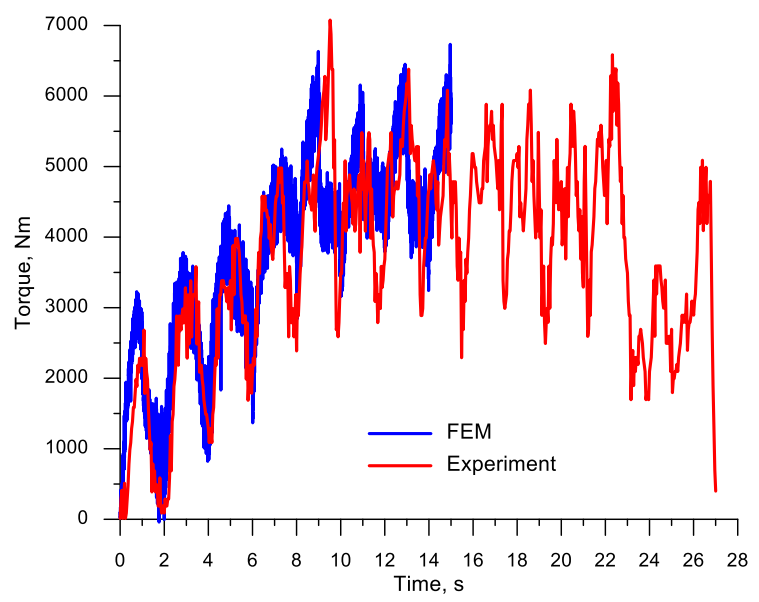

Figure 8. Comparison of FEM and experimental torques in helical rolling of $57 \mathrm{~mm}$ diameter balls. 




Figure 9. Comparison of FEM and experimental radial loads in helical rolling of $57 \mathrm{~mm}$ diameter balls.

The designed model allows for observing the changes in the formed material during the rolling process. For example, in Figure 10 changes in temperature, effective strain and damage function (according to Cockroft-Latham criterion) are shown in the longitudinal (axial) section of the workpiece. It can also be observed that the places most susceptible to changes are the areas of neckings (connectors of balls), where the deformations are at their highest values and the critical value of the damage function is exceeded, which eventually leads to the material separating. In those areas, as a result of an exchange of plastic deformation work and friction work into heat, the temperature of the material is higher than billet's temperature (even about $50^{\circ} \mathrm{C}$ ).

a)



b)

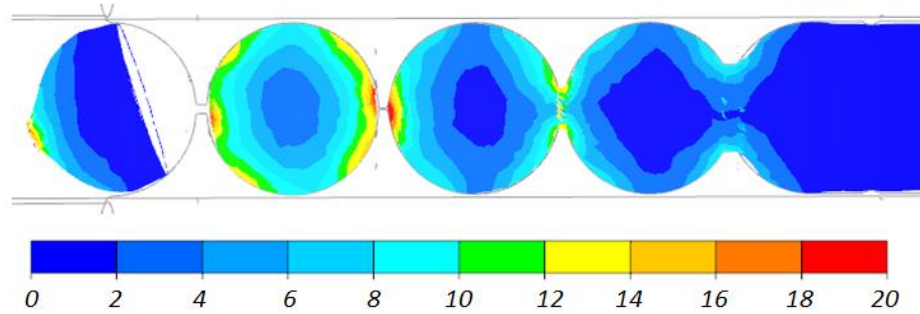

c)

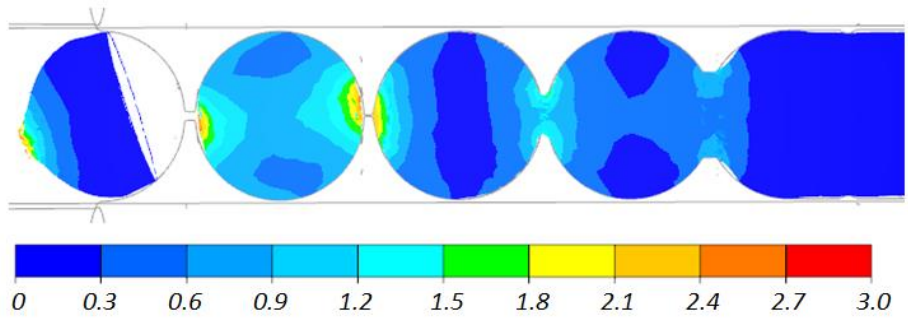

Figure 10. Example results obtained from FEM analysis of helical rolling of $57 \mathrm{~mm}$ diameter balls: (a) temperature distribution (in ${ }^{\circ} \mathrm{C}$ ); (b) distribution of effective strain; (c) distribution of the damage function according to Cockroft-Latham criterion. 
Concluding validation results, it must be stated that the developed numerical model of a helical-wedge rolling process for producing balls shows a perfect agreement with the real process. Therefore, it is recommended that this model should be used in research on helical-wedge rolling.

\section{Numerical Analysis of a Helical-Wedge Rolling Process for Producing Balls with a Diameter of $125 \mathrm{~mm}$}

A numerical analysis was performed to investigate a helical-wedge rolling process for the biggest balls, i.e., balls with a diameter of $125 \mathrm{~mm}$. The objective of the analysis was to determine the effect of the flange shape on the helical-wedge rolling process. Three variants of the tools were considered (schematically shown in Figure 11), all having the same overall dimensions $\left(\varnothing 700 \times 600 \mathrm{~mm}^{2}\right.$ ).

The first of the analyzed cases was a classical solution widely used in industrial conditions. In this case, as shown in Figure 12, a material volume $V$ formed with a single flange can be calculated at any stage of the process by the following formula:

$$
V=\frac{2}{3} \pi \sqrt{R^{2}-(R-h)^{2}}\left[2 R^{2}-(R-h)^{2}\right]+\pi b(R-h)^{2},
$$

where: $R$-ball radius, $b$-flange width, $h$-flange height.

Assuming that the volume $V$ is equal to the volume of a formed ball (with the bridge), $V_{b}$, it is possible to calculate flange parameters, $h$ and $b$. To this end, one must first adopt a forming length described with the rotation angle of the roll. After that, assuming an increase in the flange height on the applied forming length, it is possible to calculate the flange width $b$ :

$$
b=\frac{V_{b}-\frac{2}{3} \pi \sqrt{R^{2}-(R-h)^{2}}\left[2 R^{2}-(R-h)^{2}\right]}{\pi(R-h)^{2}} .
$$

In Variant II, the flange width is reduced in the stage when the tool intensively cuts into the workpiece, i.e., during the first revolution of the rolls (this operation is often applied in industrial practice). This effect is produced by introducing into the roll pass a cylindrical part with a width $b_{c}$ (Figure 13). Here, the volume of material constrained in the roll pass is described with the following relationship:

$$
V=V_{1}+V_{2}+V_{c}+V_{b 1}+V_{b 2}
$$

where:

$V_{1}$ is the volume of the cylindrical bridge connecting adjacent balls, which are formed by the flange at a rotation angle $\varphi$, where:

$$
V_{1}=\pi\left(R-h_{\varphi}\right)^{2} \frac{b_{\varphi}}{2}
$$

$V_{2}$ is the volume of the cylindrical bridge connecting adjacent balls, which are formed by the flange at a rotation angle $\varphi+360^{\circ}$, where:

$$
V_{2}=\pi\left(R-h_{\varphi+360^{\circ}}\right)^{2} \frac{b_{\varphi+360^{\circ}}}{2}
$$

$V_{c}$ is the volume of the cylindrical part between spherical parts, which are formed by adjacent flanges, where:

$$
V_{c}=\pi R^{2} b_{c} ;
$$

$V_{b 1}$ is the spherical part formed by the flange at a rotation angle $\varphi$, where:

$$
V_{b 1}=\frac{\pi}{3}\left[2 R^{3}-\left(R-\sqrt{R^{2}-\left(R-h_{\varphi}\right)^{2}}\right)^{2}\left(2 R+\sqrt{R^{2}-\left(R-h_{\varphi}\right)^{2}}\right)\right] ;
$$


$V_{b 2}$ is the spherical part formed by the flange at a rotation angle $\varphi+360^{\circ}$, where:

$$
V_{b 2}=\frac{\pi}{3}\left[2 R^{3}-\left(R-\sqrt{R^{2}-\left(R-h_{\varphi+360^{\circ}}\right)^{2}}\right)^{2}\left(2 R+\sqrt{R^{2}-\left(R-h_{\varphi+360^{\circ}}\right)^{2}}\right)\right] .
$$
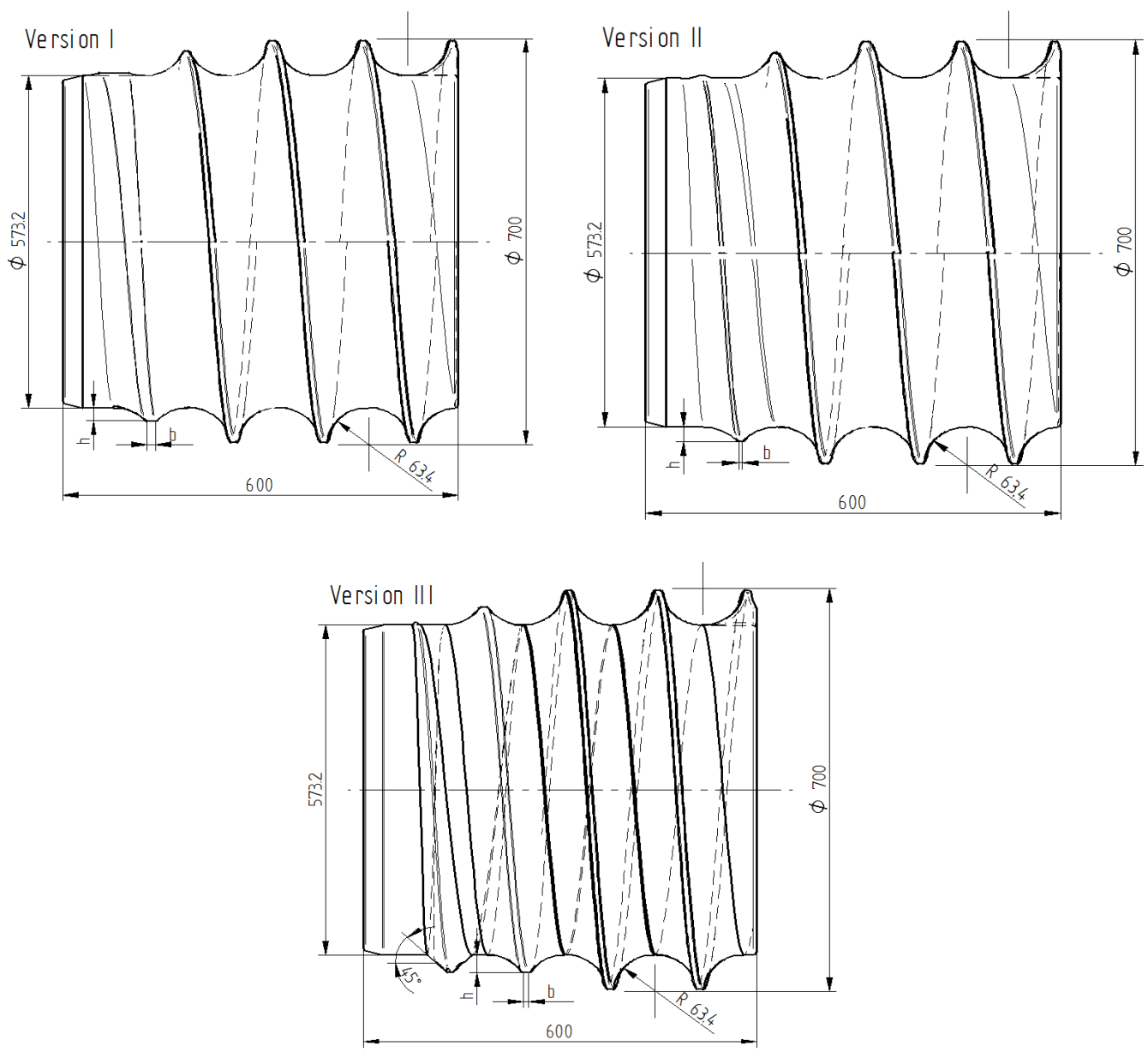

Figure 11. Schematic design of helical rolls (I-III) for rolling of $125 \mathrm{~mm}$ diameter balls.

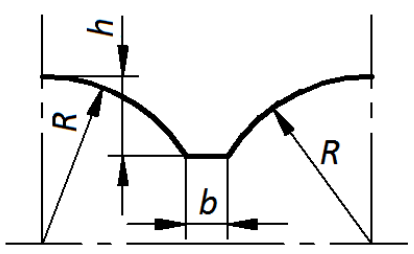

Figure 12. Flange profile used in helical rolling of balls (Variant I).



Figure 13. Schematic diagram for calculating material volume confined in the roll pass in helical rolling of balls (Variant II). 
Equations (5) $\div$ (9) use the following denotations: $\varphi$-angle of rotation of the roll, $b$-flange width, $h$-flange height, $b_{c}$ —width of the cylindrical part in the roll pass, $R$-ball radius.

In Variant II, height and width of the flange (for a given rotation angle $\varphi$ ) are given arbitrarily. In this way, assuming that the volume of material constrained in the roll pass is equal to the ball volume $V_{b}$, one can calculate width of the cylindrical part of the roll pass. This is done using the formula:

$$
b_{c}=\frac{V_{b}-V_{1}-V_{2}-V_{b 1}-V_{b 2}}{\pi R^{2}} .
$$

In Variant III, the wedge-flange is made identical (in terms of scale) to that employed in the rolling of $57 \mathrm{~mm}$ diameter balls, shown in Figure 2.

Figures 14 and 15 compare the width $b$ and the height $h$ of a helical-flange depending on the process variant and the applied angle of rotation of the rolls. The data in the figures demonstrate that the flange used in Variants I and II reaches its maximum height after the rolls have performed one and a half revolutions, while in Variant III-only after two revolutions of the rolls. The flange width is the smallest in Variant III and the biggest in Variant I. In the sizing stage (when $\varphi>720^{\circ}$ ), the flange size is the same in all investigated cases.

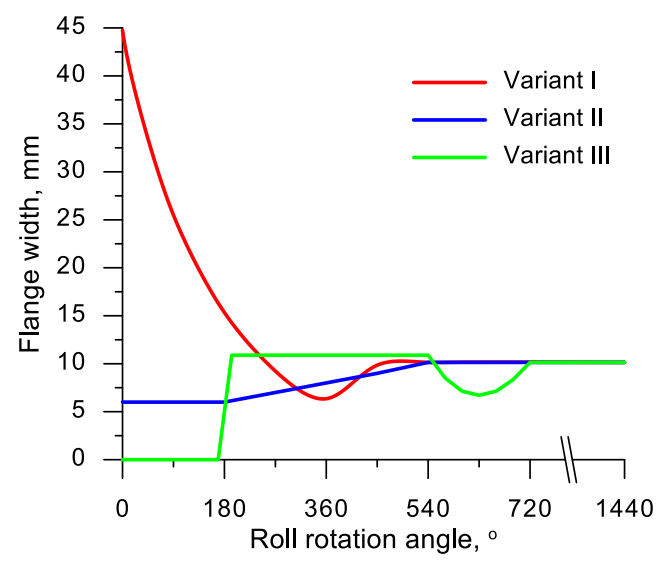

Figure 14. Flange width versus roll rotation angle.



Figure 15. Flange height versus roll rotation angle.

The effect of flange shape on the helical-wedge rolling process for producing $125 \mathrm{~mm}$ diameter balls was verified via numerical simulations performed with the use of numerical models identical to those used in the modelling of rolling of $57 \mathrm{~mm}$ diameter balls. Apart from the size of the tools, the differences concerned the grade of material $(70 \mathrm{Mn} 3$ steel), the rotational speed of the rolls (53 rev/ $\mathrm{min})$, the tool temperature $\left(250{ }^{\circ} \mathrm{C}\right)$ and the billet dimensions $\left(\varnothing 120 \times 600 \mathrm{~mm}^{2}\right)$. In the 
simulations, the time of rolling was set equal to $6 \mathrm{~s}$, which corresponds to 5.3 revolutions of the rolls and is sufficient to form a complete ball.

Figure 16 shows the changes in workpiece shape in a helical-wedge rolling process for three investigated tool variants. Analyzing the data in the figure, one can observe that as the flange cuts into the workpiece, the material is pushed away from the tools, which is undesired. This displacement of metal leads to underfill and decreases the workpiece-rotating friction forces. The highest displacement is observed for Variant II, while the lowest-for Variant III. Notwithstanding the above, all balls obtained from the three investigated variants of the process have a correct shape and meet the shape tolerance requirement for balls of this size, this tolerance being equal to $\pm 4 \mathrm{~mm}$.

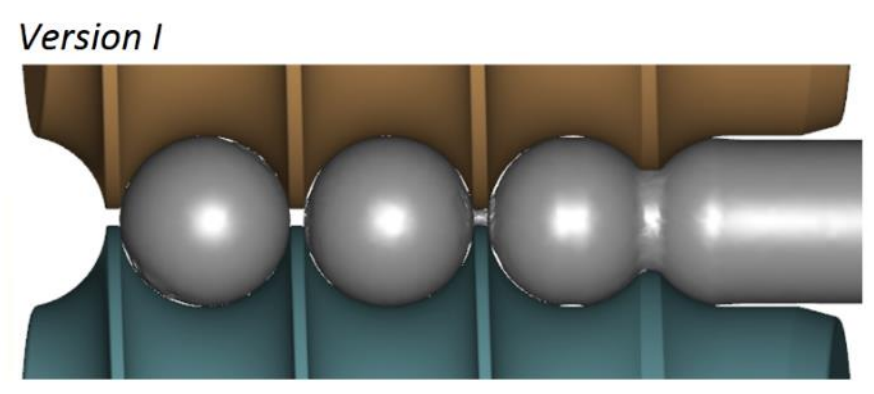

\section{Version II}
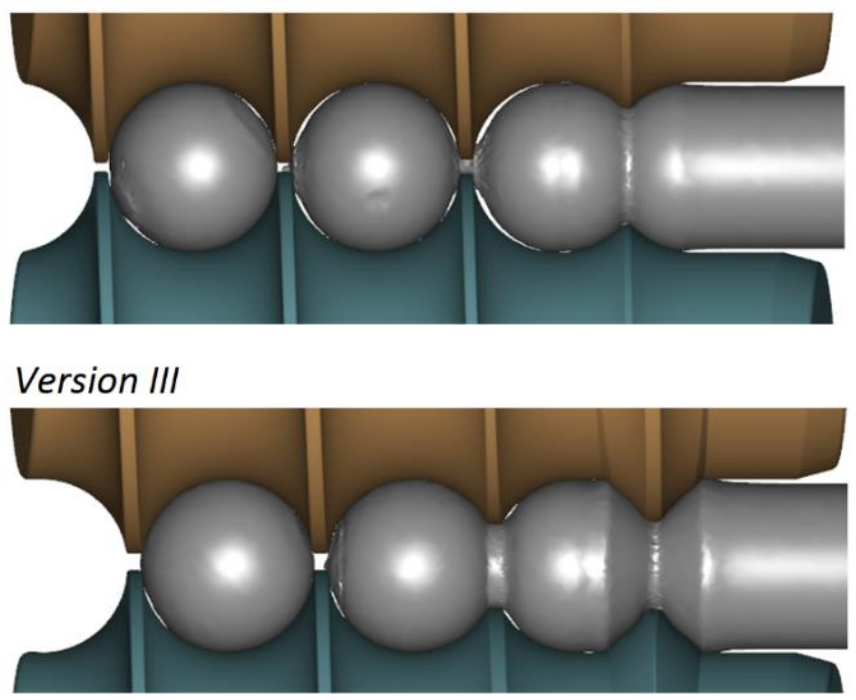

Figure 16. Shape of $125 \mathrm{~mm}$ diameter balls obtained in investigated variants of helical rolling.

A change of the flange shape leads to changes in the distribution of effective strains-Figure 17. As for the standard flanges (Variants I and II), the strains are distributed in layers and are the lowest in the center of the ball, while the highest strains occur on the side of the ball (separation point). The highest differences in the strains can be observed in Variant I when the tools have the widest flanges. This pattern of strain distribution changes when the wedge-flange is used. The workpiece material is more uniformly deformed, which definitely results from the change in metal flow kinematics. More specifically, as the tool cuts into the workpiece, metal starts to flow in both radial and axial directions. This variant of the material flow allows not only for reducing the diameter of the billet, but also material upsetting. Therefore, it is possible to manufacture a product with a bigger diameter than billet's. In contrast, the use of standard flanges (Variants I and II) only causes a radial metal flow.

Figure 18 shows the damage functions (according to the Cockroft-Latham criterion) in the axial section of a workpiece. Analyzing the behavior patterns of the damage function in these figures, one can observe that the damage function does not exceed the assumed critical value of 3 in any of the investigated cases. This means that produced balls should be free from undesired internal cracking. 
As expected, the damage function is the highest in the vicinity of the connecting bridges, which results from the fact that this is the region where the balls get separated.

Figures 19 and 20 show the numerical radial loads and torques in three investigated cases of helical-wedge rolling of $125 \mathrm{~mm}$ diameter balls. Variations in these parameters have a distinctive periodical pattern, due to the flange's periodical (every complete revolution) cutting into the workpiece. The highest variations in the load and torque are observed for Variant I, while the smallest - for Variant III. The pattern of variations in the force parameters also indicates the necessity of using wedge-flanges in helical-wedge rolling of balls. Moreover, given the periodical variations in torque, it is recommended that the helical-wedge rolling process for producing balls should be performed using rolling mills equipped with flywheels, as this would help reduce the engine power of these machines.

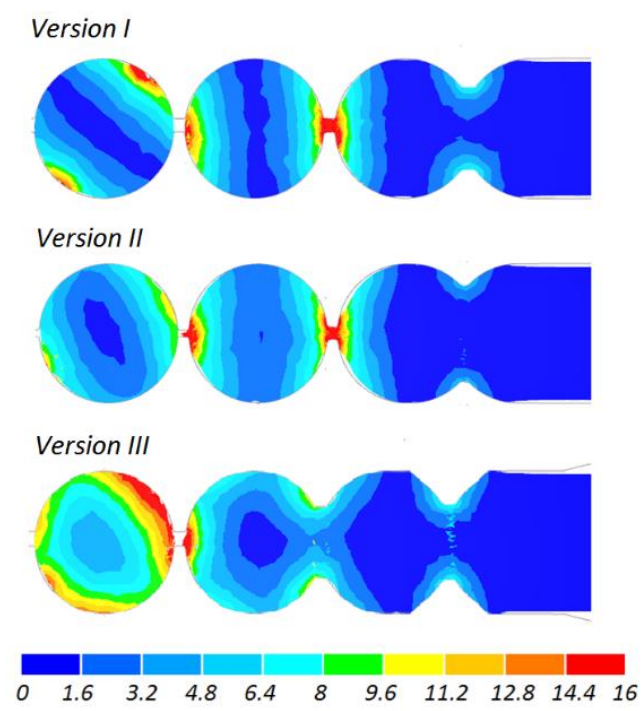

Figure 17. Effective strains in the workpiece in investigated variants of a helical rolling process for $125 \mathrm{~mm}$ diameter balls.

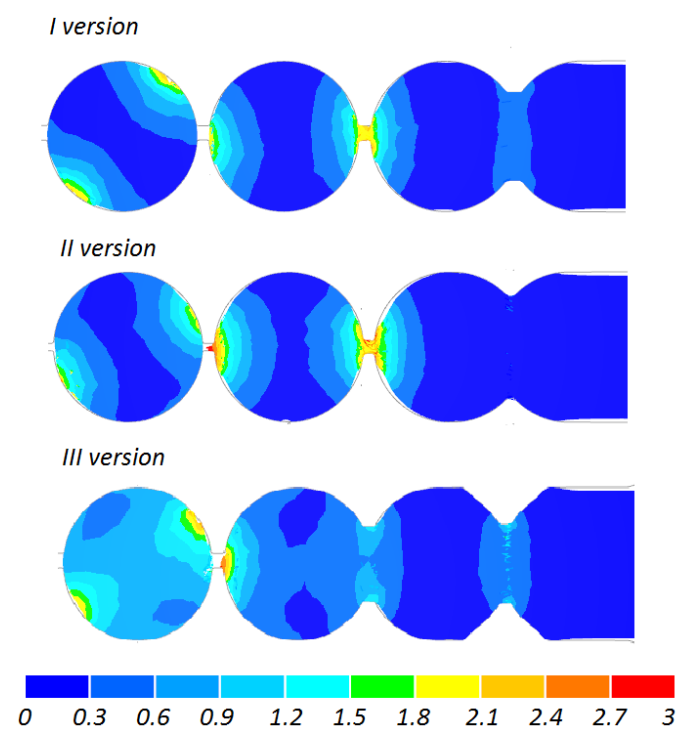

Figure 18. Damage function (acc. to Cockroft-Latham criterion) in the workpiece in investigated variants of a helical rolling process for $125 \mathrm{~mm}$ diameter balls. 


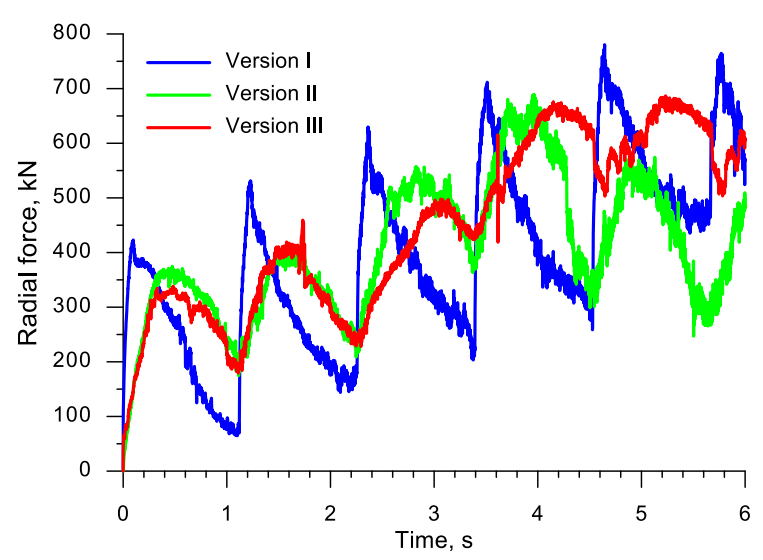

Figure 19. Radial force variations in investigated variants of a helical rolling process for $125 \mathrm{~mm}$ diameter balls.



Figure 20. Torque variations in investigated variants of a helical rolling process for $125 \mathrm{~mm}$ diameter balls.

\section{Conclusions}

Taking into account obtained numerical results and experimental findings, the following conclusions can be drawn:

- The developed numerical model of a helical-wedge rolling process for producing balls enables both the examination of changes in the ball shape during the process and the simulation of a correct ball separation operation.

- Numerical force parameters (radial load and torque) show a very agreement with experimental findings.

- Helical-wedge rolling can be performed using flange tools of different shapes and sizes; the three tool variants investigated in this study enable the forming of $125 \mathrm{~mm}$ diameter balls that are free from surface defects and internal cracking.

- The use of wedge-flanges ensures optimal filling, uniform deformation of the material and stability of the force parameters in the process.

- Variations in the force parameters in helical-wedge rolling have a distinctive periodic pattern caused by the periodic cutting of the flange tool into the workpiece; hence, it is recommended that helical-wedge rolling of balls should be performed on rolling mills equipped with flywheels.

- The designed numerical model of the ball-forming process will be used in the future analysis of helical rolling process of balls with a diameter bigger than that of the billet. 


\section{Patents}

The list of patents resulting from the work reported in this article is following:

- $\quad$ Pater, Z.; Tomczak, J. Tool for skew rolling of ball type product. Polish patent no PL 219678, 2014.

- $\quad$ Pater, Z.; Tomczak, J. Multi coins tool for multiple skew rolling. Polish patent no PL 221927, 2015.

Author Contributions: The research was conceived by Z.P. and J.T. The methodology was planned by Z.P. and J.T. Theoretical analysis was performed by Z.P. Experimental tests were carried out by J.T, J.B. and T.B. The manuscript was written by Z.P.

Funding: This research was funded by the National Science Centre Poland, grant number 2017/25/B/ST8/00294.

Conflicts of Interest: The authors declare no conflict of interest.

\section{References}

1. Shor, E.R. New Rolling Processes, 1st ed.; Metallurgizdat: Moscow, Russia, 1960. (In Russian)

2. Ren, X.; Liu, Y. Study on the Influence of Deforming Velocity on Steel Ball Quality Based on DEFORM. Appl. Mech. Mater. 2012, 117-119, 1806-1809. [CrossRef]

3. Du, S.; Ren, X.; Liu, Y. Analysis of Factors Influencing the Skew Rolling Ball Quality. Mach. Des. Manuf. 2013, 2, 248-250.

4. Pater, Z.; Tomczak, J.; Bartnicki, J.; Lovell, M.R.; Menezes, P.L. Experimental and numerical analysis of helical-wedge rolling process for producing steel balls. Int. J. Mach. Tool Manuf. 2013, 67, 1-7. [CrossRef]

5. Tomczak, J.; Pater, Z.; Bulzak, T. Designing of screw impressions in helical rolling of balls. Arch. Civ. Mech. Eng. 2014, 14, 104-113. [CrossRef]

6. Pater, Z. A thermomechanical analysis of the multi-wedge helical rolling (MWHR) process for producing balls. Metalurgija 2016, 55, 233-236.

7. Cao, Q.; Hua, L.; Qian, D. Finite element analysis of deformation characteristics in cold helical rolling of bearing steel-balls. J. Cent. South Univ. 2015, 22, 1175-1183. [CrossRef]

8. Filippova, M.V.; Temlyantsev, M.V.; Pretyat'ko, V.N.; Prudkii, E.E. Rolling of Metal Balls. Steel Transl. 2017, 47, 435-439. [CrossRef]

9. Li, H.; Fu, M.W.; Lu, J.; Yang, H. Ductile fracture: Experiments and computations. Int. J. Plast. 2014, 27, 147-180. [CrossRef]

10. Pater, Z.; Walczuk, P.; Lis, K.; Wójcik, Ł. Preliminary analysis of a rotary compression test. Adv. Sci. Technol. Res. J. 2018, 12, 77-82. [CrossRef]

11. Novella, M.F.; Ghiotti, A.; Bruschi, S.; Bariani, P.F. Ductile damage modeling at elevated temperature applied to the cross wedge rolling of AA6082-T6 bars. J. Mater. Process. Technol. 2015, 222, 259-267. [CrossRef]

12. Pater, Z. Analysis of metal cracking in cross-wedge rolling process. Hutnik, Wiadomości Hutnicze 2007, 74, 588-595. (In Polish)

(c) 2018 by the authors. Licensee MDPI, Basel, Switzerland. This article is an open access article distributed under the terms and conditions of the Creative Commons Attribution (CC BY) license (http:/ / creativecommons.org/licenses/by/4.0/). 